\title{
IMÁGENES DE PARÁSITOS CAUSANTES DE FASCIOLOSIS, CISTICERCOSIS, HIDATIDOSIS Y TOXOCAROSIS
}

\section{[PICTURES OF PARASITES CAUSING FASCIOLIASIS, CYSTICERCOSIS, HYDATID DISEASE AND TOXOCAROSIS]}

\author{
Rito Zerpa ${ }^{1,2, a}$, Yrma A. Espinoza ${ }^{2, b}$, Alina Huiza ${ }^{2, b}$, Elsa Ore1,c, William H. Roldán²,c
}

Las zoonosis son enfermedades infecciosas transmisibles en condiciones naturales entre los animales y el hombre, que son importantes no solo para la salud humana y animal, sino también por sus repercusiones económicas en la actividad ganadera.

Los países subdesarrollados son afectados frecuentemente por las zoonosis parasitarias y el Perú en particular es uno de los países endémicos con mayores tasas de estas enfermedades. En este número de la Revista se presentan cuatro de las principales zoonosis que afectan a nuestra población: fasciolosis, hidatidosis, cisticercosis y toxocariosis ${ }^{(1)}$.

En esta galería fotográfica se presenta en imágenes la experiencia del Instituto Nacional de Salud del Niño y

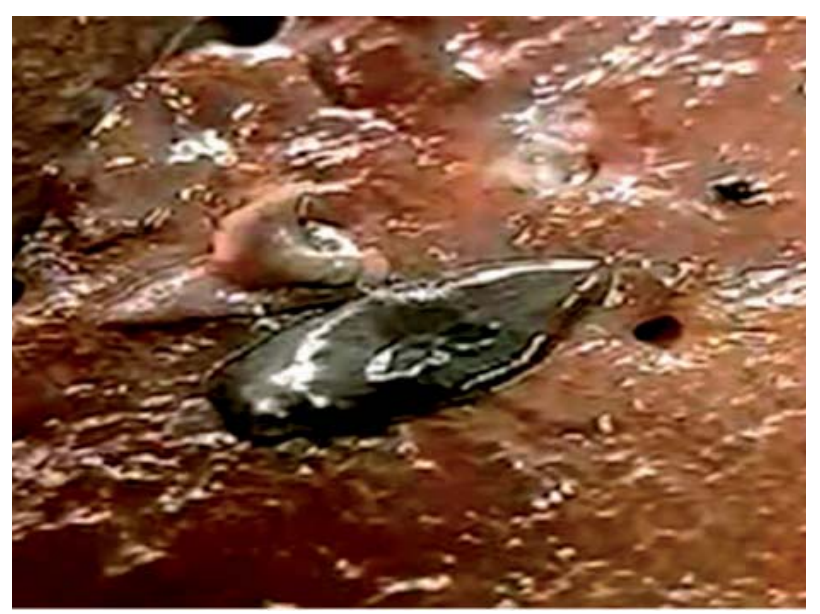

Figura 1. Adulto de Fasciola hepatica emergiendo del canalículo biliar.

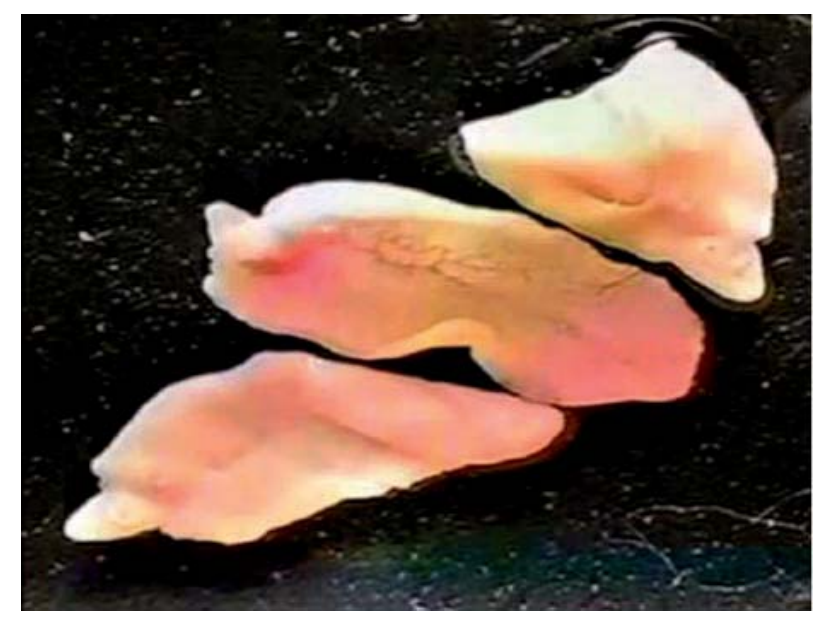

Figura 2. Estadio adulto de Fasciola hepatica (2 a $4 \mathrm{~cm}$ ) obtenido de canalículo biliar de ganado vacuno.

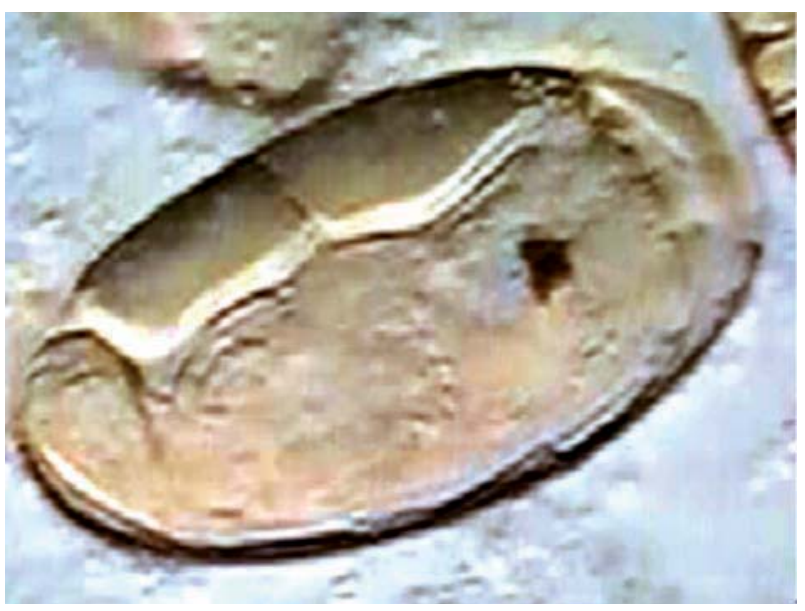

Figura 3. Huevo con miracidio (in vivo) de Fasciola hepatica, que mide $110 \mu \mathrm{m}$.

Servicio de Microbiología, Instituto Nacional de Salud del Niño, Lima, Perú.

2 Instituto de Medicina Tropical “Daniel A. Carrión”, Universidad Nacional Mayor de San Marcos, Lima, Perú.

a Médico Patólogo Clínico; ' Bióloga, ' Tecnólogo Médico. 


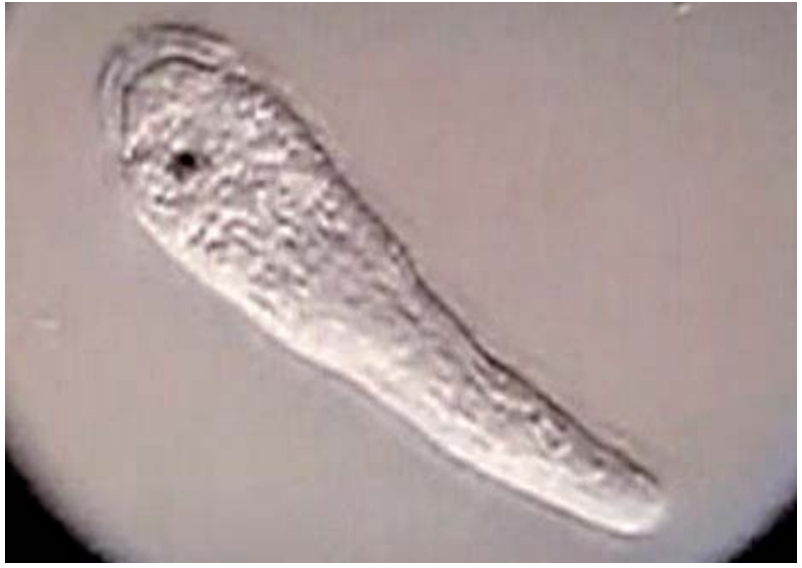

Figura 4. Miracidio de Fasciola hepatica (in vivo), se observa cilios y mancha ocular.

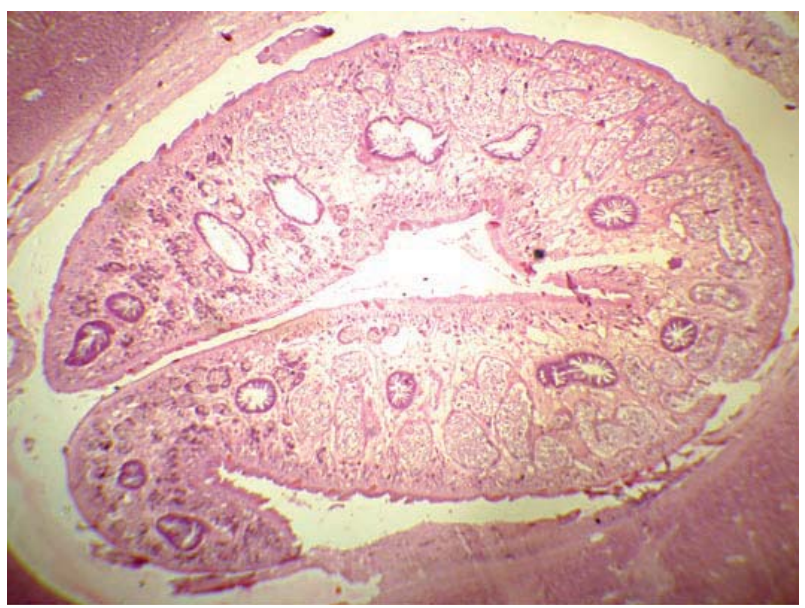

Figura 5. Corte histológico de canalículo biliar con Fasciola hepatica (10X). Tinción H.E.

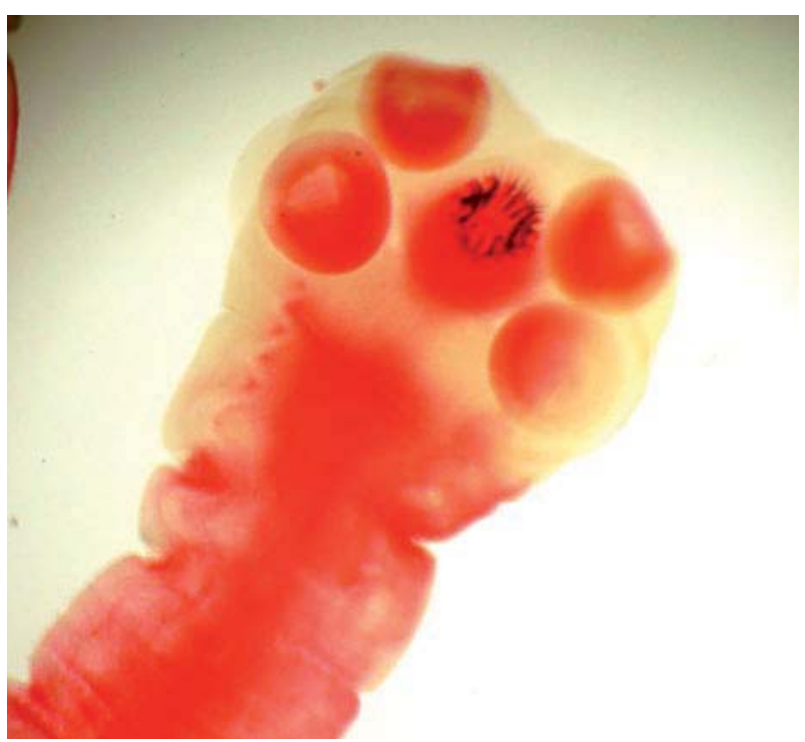

Figura 6. Escólex de Taenia solium, se observa las cuatro ventosas y rostellum con la corona de ganchos (10X).

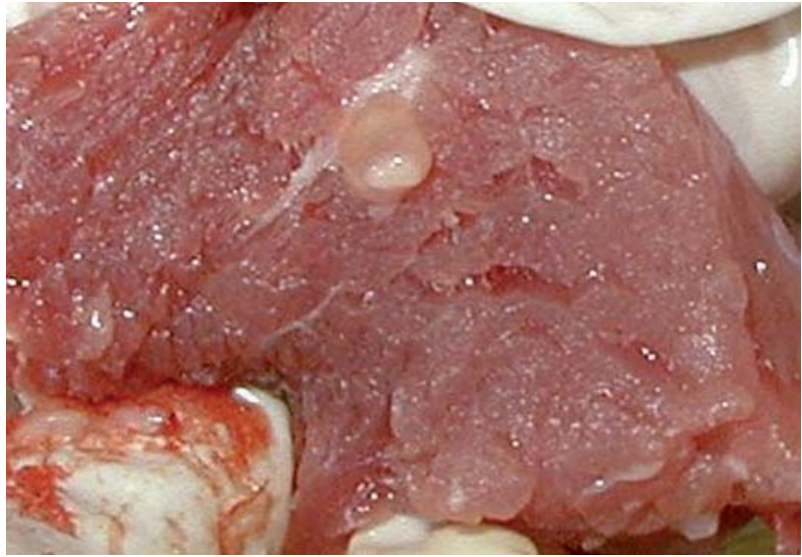

Figura 7. Cisticercus cellulosae $(1 \mathrm{~cm})$ en carne de cerdo, se observa la mancha blanca que corresponde al escólex invaginado, estadio infectante para el hombre.

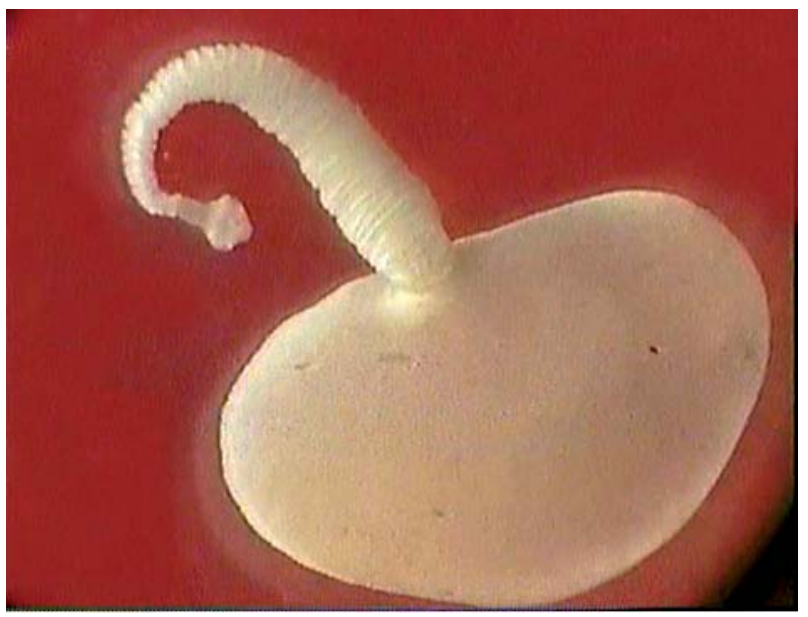

Figura 8. Cisticercus cellulosae evaginado con bilis, se observa el escólex con ventosas y rostellum con corona de ganchos (10X).

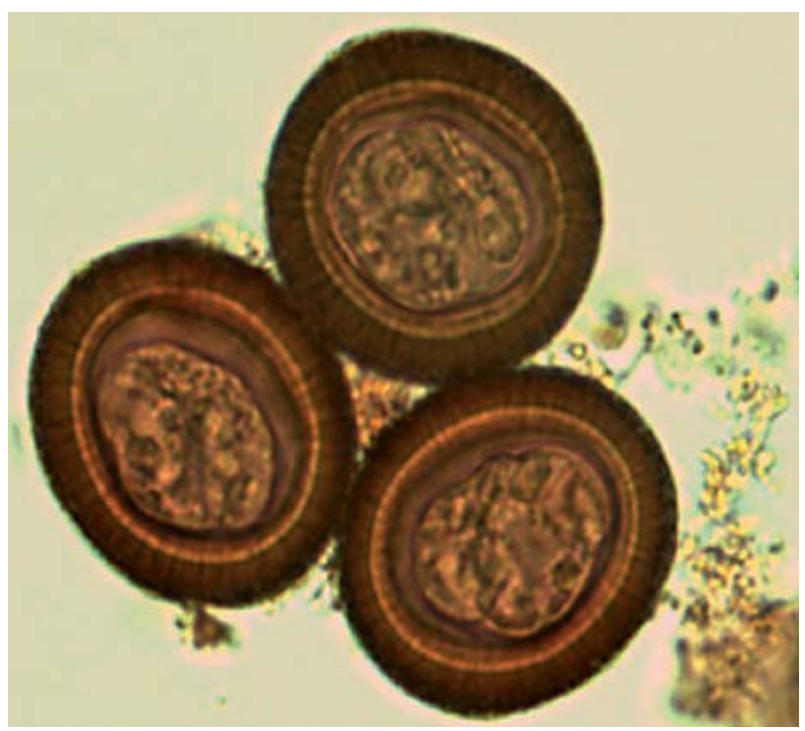

Figura 9. Huevos de Taenia sp. $(45 \mu \mathrm{m})$, estadio infectante para el cerdo y el hombre. 


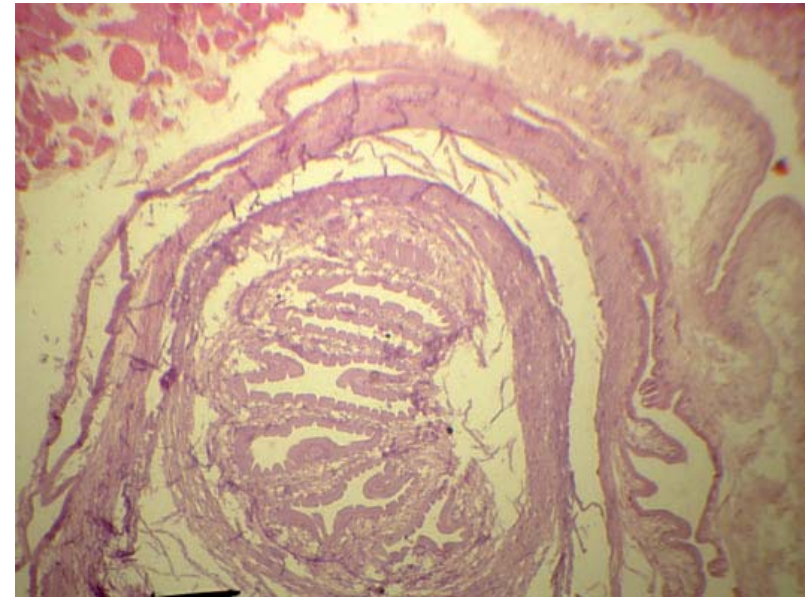

Figura 10. Corte histológico de Cisticercus cellulosae (10X). Tinción H.E.

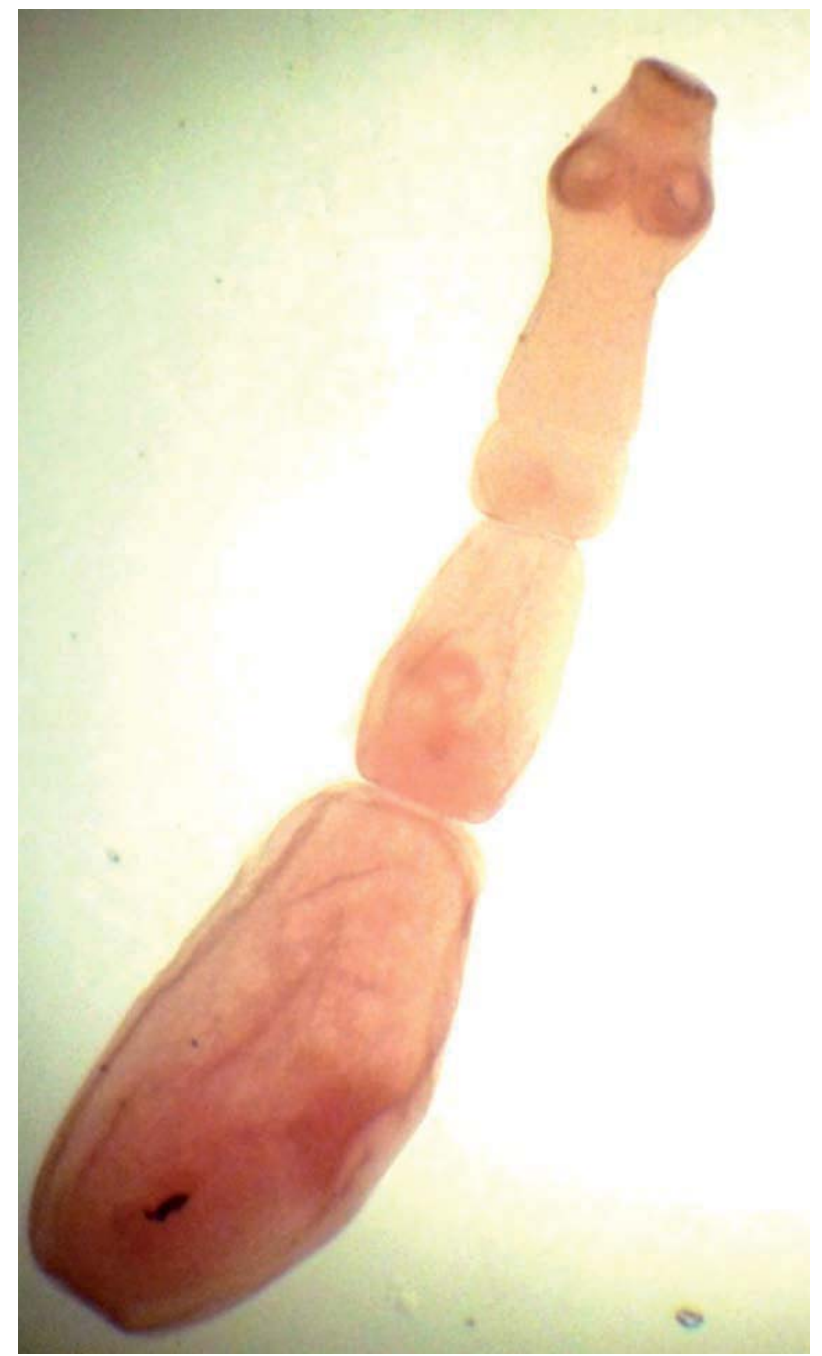

Figura 11. Adulto de Echinococcus granulosus, mide $0,5 \mathrm{~cm}$ obtenido de intestino de perro, se observa el escólex con cuatro ventosas y el rostellum con dos coronas de ganchos, cuello, proglótidos inmaduro, maduro y grávido, coloreado con carmín de Semichón.

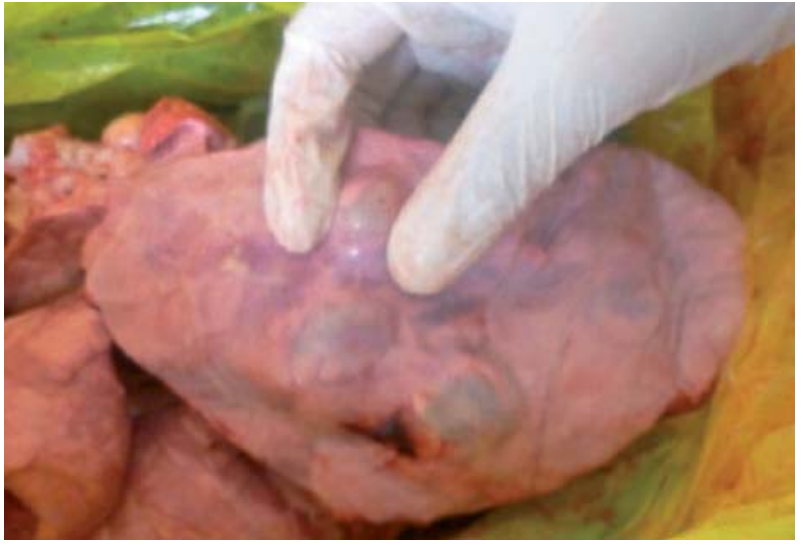

Figura 12. Quiste hidatídico localizado en tejido pulmonar de ganado ovino.

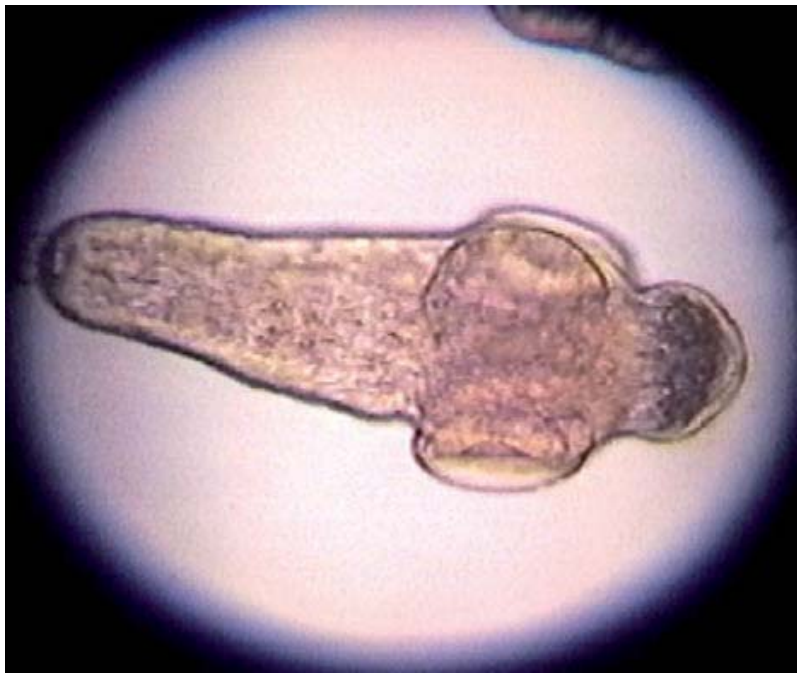

Figura 13. Protoescólice de Echinococcus granulosus (100 $\mu \mathrm{m})$ (arenilla hidatídica), estadio infectante para los cánidos.

del Instituto de Medicina Tropical "Daniel A. Carrión" de la Universidad Nacional Mayor de San Marcos con diferentes técnicas que permiten una mejor visualización microscópica de diferentes patógenos, tanto en imágenes bi y tridimensionales.

En las figuras 1 a 5 se pueden apreciar a la Fasciola hepática tanto a nivel macroscópico como microscópico del parásito y en cortes histológicos. De igual manera, se aprecia a la Taenia solium en sus formas adultas como larvales, más conocidas como cisticercos (Figuras 6,7,8 y 10) y huevos de Taenia sp (Figura 9). La hidatidosis es causada por el Echinococcus granulosus que se exponen en las figuras 11 a 14 . Finalmente, se presentan en las figuras 15 a 18 a Toxocara canis, parásito frecuente pero poco buscado, que puede en algunos casos, llevar a la ceguera. 


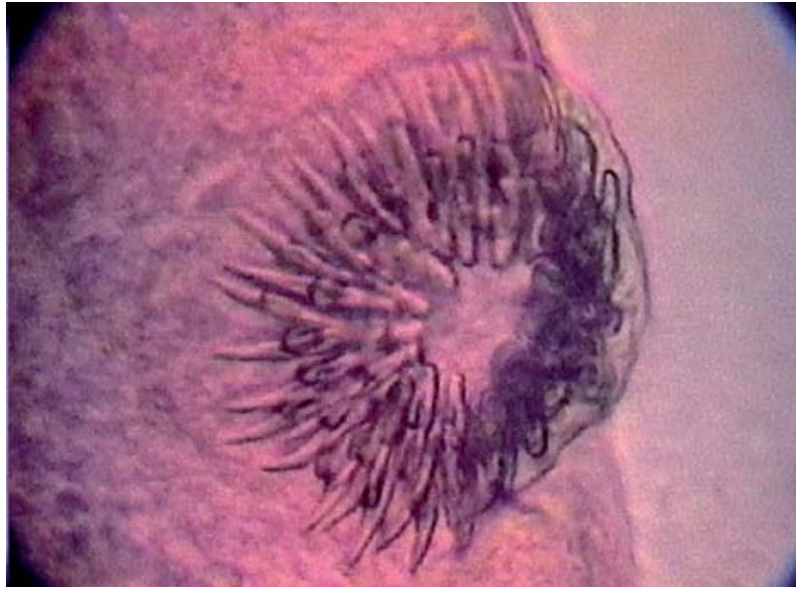

Figura 14. Corona de ganchos del protoescólice de Echinococcus granulosus. Preparación en montaje húmedo con safranina al 0,25\%.

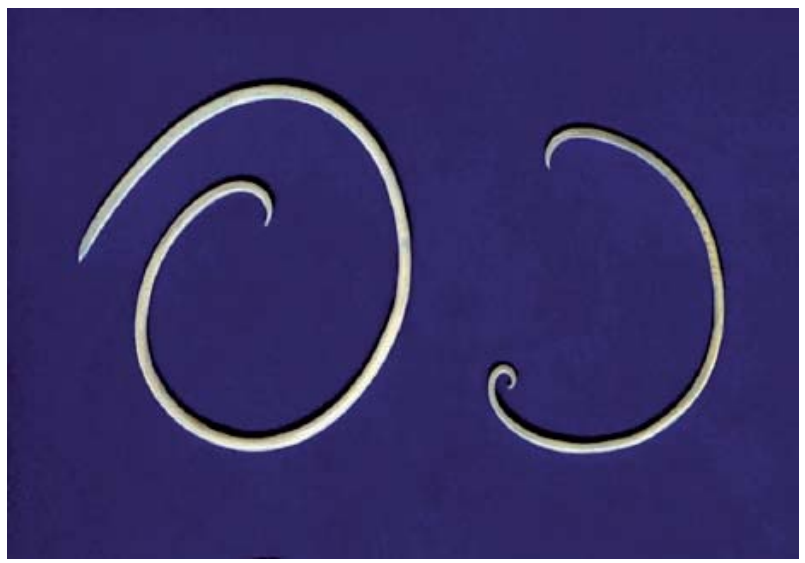

Figura 15. Adultos hembra $(12 \mathrm{~cm})$ y macho $(9 \mathrm{~cm})$ de Toxocara canis.

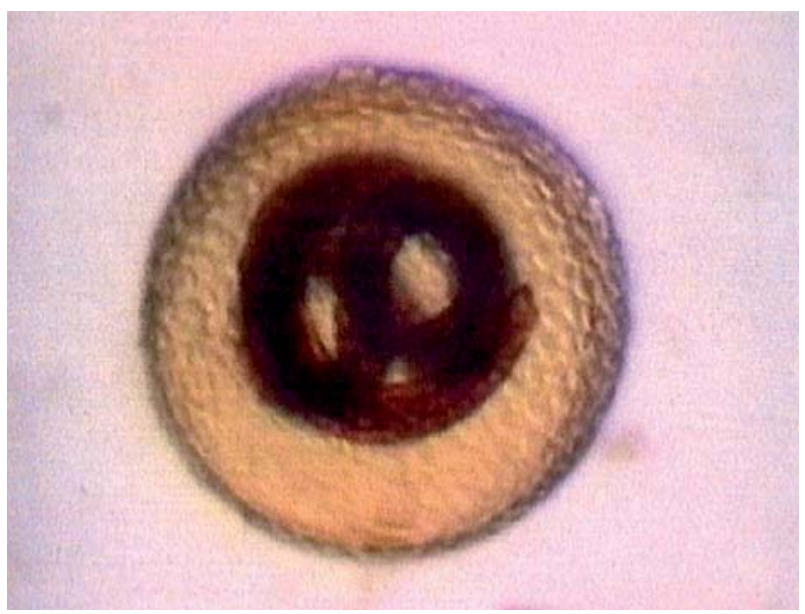

Figura 16. Huevo larvado $(80 \mu \mathrm{m})$ de Toxocara canis, estadio infectante para el perro y el hombre. Preparación en montaje húmedo con safranina al $0,25 \%$.

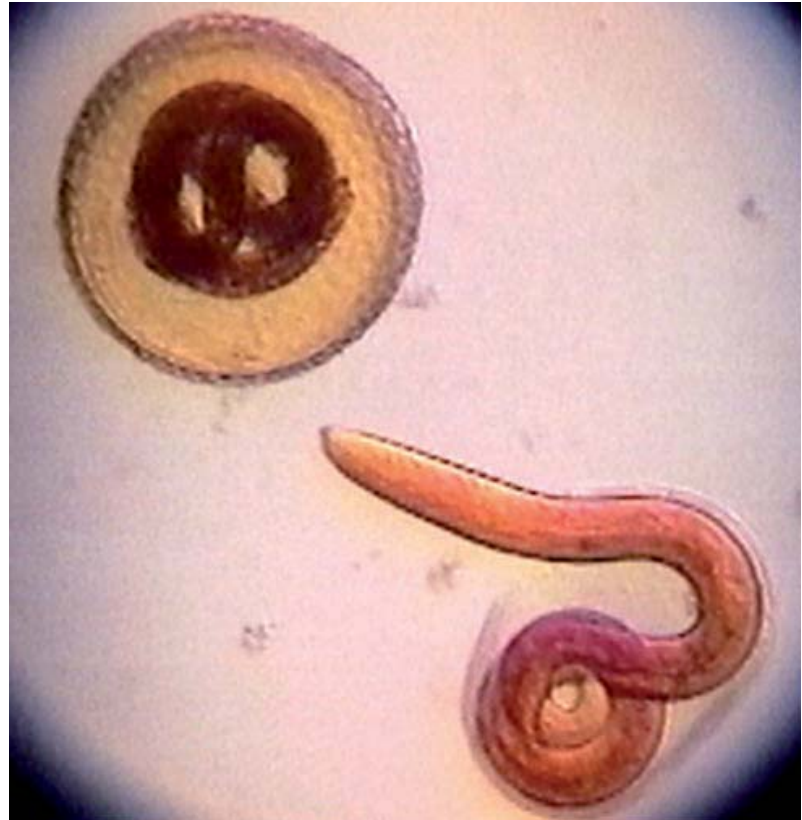

Figura 17. Huevo larvado y larva eclosionada de huevo de Toxocara canis. Preparación en montaje húmedo con safranina al $0,25 \%$

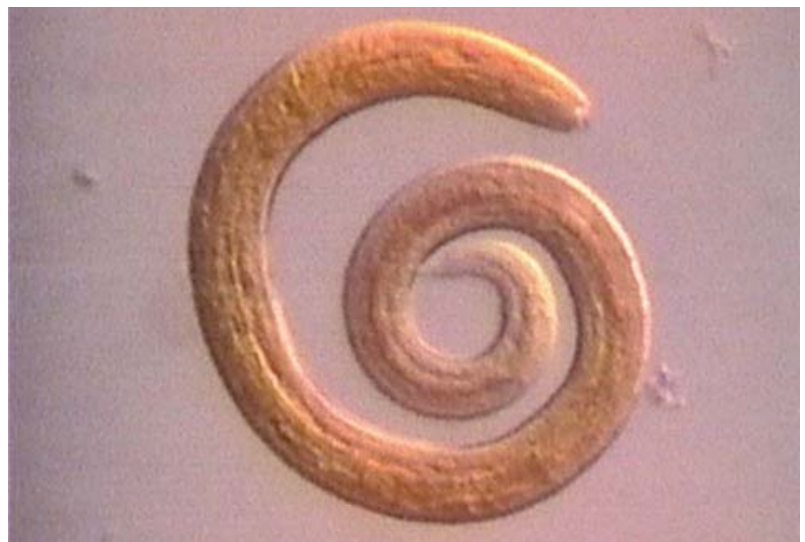

Figura 18. Larva de segundo estadio $(350 \mu \mathrm{m})$ de Toxocara canis (in vivo).

\section{REFERENCIAS BIBLIOGRÁFICAS}

1. Naquira C. Las zoonosis parasitarias: problema de salud pública en el Perú. Rev Peru Med Exp Salu Publica. 2010;27(4):494-97.

2. Zerpa R. Rompiendo paradigmas en la observación microscópica. Comunicación preliminar. An Fac Med (Lima). 2003;64(4):267-73.

3. Zerpa R. Imágenes especiales de microorganismos obtenidas con microscopia convencional. Rev Mex Patol Clin. 2010;57(4):170-74.

Correspondencia: Rito Zerpa Larrauri

Correo electrónico: rzerpa43@yahoo.com 